\title{
Metformin and Calcitriol Enhance 5-Fluorouracil Tumoricidal Effects in Colon Cancer By Modulating The PI3K/Akt/PTEN/mTOR Network
}

Riyad Almaimani

Umm Al-Qura University

Akhmed Aslam

Umm Al-Qura University

Jawwad Ahmad

Umm Al-Qura University

Mahmoud Zaki El-Readi

Umm Al-Qura University

Mohamed El-Boshy

Mansoura University

Abdelghany $\mathrm{H}$. Abdelghany

Alexandria University

Shakir Idris

Umm Al-Qura University

Mai Alhadrami

Umm Al-Qura University

Mohammad Althubiti

Umm Al-Qura University

Hussain Almasmoum

Umm Al-Qura University

Mazen M Ghaith

Umm Al-Qura University

Mohamed E Abdallah

Umm Al-Qura University

Safaa Y Eid

Umm Al-Qura University

Bassem Refaat ( $\nabla$ barefaat@uqu.edu.sa )

Umm Al-Qura University

Research Article 
Keywords: Chemoresistance, Calcitriol, Metformin, Cell cycle, Apoptosis, Phosphatidylinositol-3-kinase, Protein kinase B, Mammalian target of rapamycin

Posted Date: January 3rd, 2022

DOI: https://doi.org/10.21203/rs.3.rs-1204775/v1

License: (c) (1) This work is licensed under a Creative Commons Attribution 4.0 International License. Read Full License 


\section{Abstract}

Purpose: Chemoresistance to 5-Fluorouracil (5-FU) is common during colorectal cancer (CRC) treatment. This study measured the chemotherapeutic effects of 5-FU, calcitriol, and/or metformin single/dual/triple regimens as complementary/alternative therapies.

Methods: Ninety male mice were divided into: negative and positive (PC) controls, 5-FU, Cal, Met, 5$\mathrm{FU} / \mathrm{Cal}$, 5-FU/Met, Cal/Met, and 5-FU/Cal/Met groups. Treatments lasted four weeks following CRC induction by azoxymethane. The therapeutic regimens were also applied in the SW480 and SW620 CRC cell lines.

Results: The PC mice had abundant tumours, markedly elevated proliferation markers (survivin/CCND1) and PI3K/Akt/mTOR alongside reduced p21/PTEN/Cytochrome-C/Caspase-3 and apoptosis. All therapies reduced tumour numbers, with 5-FU/Cal/Met most prominent regimen. All protocols also decreased cell proliferation markers, inhibited PI3K/Akt/mTOR molecules, increased pro-apoptotic molecules with apoptosis index, and 5-FU/Cal/Met revealed the strongest anti-cancer effects. In vitro, all therapies equally induced G1-phase arrest in SW480 cells, whereas metformin-alone showed maximal SW620 cell numbers in G0/G1-phase. 5-FU/Met co-therapy also showed the highest apoptotic SW480 cell numbers $(13 \%)$, whilst $5-\mathrm{FU} / \mathrm{Cal} /$ Met disclosed the lowest percentage $(81 \%)$ of viable SW620 cells. Moreover, 5-FU/Cal/Met revealed maximal inhibitions of cell cycle inducers (CCND1/CCND3), cell survival (BCL2) and the PI3K/Akt/mTOR molecules alongside highest expression of cell cycle inhibitors (p21/p27), pro-apoptotic markers (BAX/Cytochrome-C/Caspase-3), and PTEN in both cell lines.

Conclusions: Metformin monotherapy was superior to calcitriol, whereas the 5-FU/metformin protocol showed better anti-cancer effects relative to the other dual therapies. However, the 5-FU/Cal/Met approach displayed the best in vivo and in vitro tumoricidal effects related to cell cycle arrest and apoptosis, justifiably by enhanced modulations of the PI3K/PTEN/Akt/mTOR pathway.

\section{Introduction}

Colorectal cancer (CRC) is the third most common malignancy and fourth among all cancer-related deaths worldwide [1,2]. Colon oncogenesis involves abnormal upregulations in cyclin D1 (CCND1), CCND3, B-cell lymphoma 2 (BCL2), and survivin proteins that promote cell cycle progression and cell survival $[3,4]$. By contrast, colon carcinogenesis is linked with reductions in cyclin-dependent kinase (CDK)-inhibitors (p21 and p27), BCL2-associated X protein (BAX), cytochrome C (Cyto-C) and caspase-3 (Casp-3) proteins [5-7]. The main drug used for treating advanced CRC, 5-Fluororacil (5-FU), inhibits cancer progression by increasing expression of CDK-inhibitors and several pro-apoptotic molecules $[8,9]$. However, 5-FU has limited therapeutic efficiency, and is associated with low success and survival rates due to development of resistance by neoplastic enterocytes $[10,11]$.

The phosphatidylinositol-3-kinase (PI3K) is a cell membrane-associated kinase and its class IA, which is a heterodimer of the $\mathrm{p} 85$ regulatory and p 110 catalytic subunits, promotes the development and 
progression of many cancers, including CRC $[12,13]$. Mammalian target of rapamycin (mTOR) is a serine/threonine kinase that acts as a downstream effector for PI3K and involved in the regulation of cell metabolism, growth, and survival $[14,15]$. The activation of PI3K is induced by phosphorylation of the p85a-subunit that activates mTOR through the intracellular mediator, protein kinase B (Akt), and hyperactivated $\mathrm{PI3K} / \mathrm{Akt} / \mathrm{mTOR}$ pathway, is linked with CRC progression and resistance to chemotherapy $[12,13]$. In contrast, the endogenous inhibitor of the PI3K/Akt/mTOR pathway, phosphatase and tensin homolog (PTEN), is commonly lost during colon carcinogenesis $[16,17]$. Moreover, the use of specific inhibitors for the PI3K/Akt/mTOR has shown promising anti-cancer effects [16,17].

Interestingly, many non-chemotherapeutic drugs exhibited potent anti-cancer activities against CRC by modulating the cell cycle regulatory and pro-apoptotic molecules alongside inhibiting the $\mathrm{PI} 3 \mathrm{~K} / \mathrm{Akt} / \mathrm{mTOR}$ pathway. In this regard, several studies revealed negative correlations between the levels of serum vitamin $D$ and $C R C$ development $[18,19]$. Moreover, active vitamin $D_{3}\left(V_{3}\right)$ attenuated the expression of the PI3K/Akt/mTOR pathway, inhibited cell proliferation and promoted apoptosis in colon cancer cell lines [20-23]. Other studies have also reported potent anti-tumorigenic effects for metformin against CRC that were portrayed by cell cycle arrest, increased apoptosis, and downregulations in the $\mathrm{PI3K} / \mathrm{Akt} / \mathrm{mTOR}$ network [24-28]. Additionally, others have shown enhanced tumoricidal actions against CRC by combining $\mathrm{VD}_{3}$ or metformin with 5 -FU [21,29-31], as well as by adding both agents together $[32,33]$.

However, none of the earlier studies explored the potential anti-cancer effects of 5-FU, $\mathrm{VD}_{3}$ and metformin triple therapy against $\mathrm{CRC}$. Hence, this study measured the tumoricidal effects related to cell cycle progression, apoptosis, and inhibition of the PI3K/Akt/mTOR pathway following 5-FU, $\mathrm{VD}_{3}$, and/or metformin single, dual, and triple therapies in vivo and in vitro.

\section{Materials And Methods}

\section{Chemicals and reagents}

Azoxymethane (AOM; \#A5486-100MG) of 98\% purity was obtained from Sigma-Aldrich Co. (MO, USA), whilst both active $\mathrm{VD}_{3}$ (Calcitriol; \#HY-10002) and metformin (\#HY-17471A) were from MedChemExpress LLC (NJ, USA). Moreover, 5-FU was purchased from Hospira Australia Ltd. (Melbourne, Australia), and all drugs were freshly prepared as per the manufacturers' instructions prior to their use. DMEM media (\#10566032), foetal bovine serum (FBS; \#A3160802), antibiotic-antimycotic solution (\#15240062) and all the utilised cell culture materials were from Thermo Fisher scientific (CA, USA).

\section{Experimental animal studies and treatment protocols}

Ninety male BALB/c mice weighing 25-30 gm each and of 12 weeks of age were equally divided into nine groups (10 mice/group) as follow: the negative (NC) and positive (PC) controls, 5-FU (5-FU), calcitriol $\left(\mathrm{VD}_{3}\right)$ and metformin (Met) monotherapy groups, the dual therapy groups that simultaneously received 
$\mathrm{VD}_{3} / 5-\mathrm{FU}(\mathrm{VF})$, Met/5-FU (MF) or $\mathrm{VD}_{3} /$ Met (VM), and the triple therapy group (VMF) that was treated with all drugs. All animal experiments were conducted in compliance with the European guidelines for the care and use of laboratory animals and the study was approved by the Committee for the Care and Use of Laboratory Animals at Umm Al-Qura University (AMSEC 19/05-10-20).

AOM was injected for two consecutive weeks (10 mg/ $\mathrm{Kg} /$ week) in all groups, expect the negative control mice, to induce CRC as previously reported [21]. The animals were observed for another 20 weeks with no intervention and received standard laboratory chow with water ad libitum. All treatment protocols were initiated at week-21 post-AOM and continued for four weeks. Freshly prepared calcitriol $(0.07 \mu \mathrm{g} / \mathrm{Kg} / \mathrm{day}$; five times/week) and metformin (430 mg/ $\mathrm{Kg} /$ day; five times/week) were administrated orally to the designated groups, and the delivered amounts were equivalent to the highest daily recommended doses for a $60 \mathrm{Kg}$ body weight adult human for calcitriol $(0.25 \mu \mathrm{g} /$ day; $0.0042 \mu \mathrm{g} / \mathrm{Kg} / \mathrm{day})$ [34] and metformin (1500 mg/day; $25 \mathrm{mg} / \mathrm{Kg} /$ day) [35] as per the dose conversion formula between human and mice [36]. 5FU was administrated to the designated groups for four successive cycles as a single weekly intraperitoneal injection (50 mg/Kg/week) as previously described [21].

\section{Types of animal samples}

Euthanasia was performed on the first day of week-25 post-AOM by cervical dislocation under anaesthesia a described earlier [21]. The colon from each animal was removed, flushed with cold phosphate buffer saline (PBS), cut longitudinally, and soaked in $10 \%$ formalin overnight between layers of filter papers [37].

\section{Gross examination and tumour counting}

The numbers of tumours/colon were grossly counted in the next morning by two researchers followed by cutting each colon into three equal parts representing proximal, middle, and distal segments to the caecum [37]. All parts were stained for 10 minutes by 1\% Alcian blue solution (\#sc-214517; Santa-Cruz Biotechnology Inc.; $\mathrm{CA}, \mathrm{USA}$ ) in $3 \%$ acetic acid ( $\mathrm{pH}$ 2.5) and then examined under a dissecting microscope (Human Diagnostics; Wiesbaden, Germany) to identify mucin depleted foci (MDF) as well as count the small tumours that were not detected by naked eye [37].

Each colonic segment was halved longitudinally, and a specimen was Swiss-rolled and processed by conventional histopathology techniques. Total RNA was extracted from the residual colonic samples with tumours by PureLink ${ }^{T M}$ RNA Mini Kit (\#12183025; Thermo Fisher Scientific), whilst total proteins were extracted by homogenising colonic specimens in RIPA lysis buffer (\#89900) with protease inhibitors (\#78429; Thermo Fisher Scientific). While the RNA quality and quantities were measured with a Qubit4 Fluorometer (Thermo Fisher Scientific), the concentrations of extracted total protein were measured by a Pierce $^{\text {TM }}$ Rapid Gold BCA Protein Kit (\#A53225; Thermo Fisher Scientific). The total protein samples were then diluted with deionized water $(2000 \mu \mathrm{g} / \mathrm{ml})$ to be used for Enzyme Linked Immunosorbent Assay (ELISA). 
Tissue sections of $5 \mu \mathrm{m}$ thickness from each colon were stained by H\&E and examined on a Leica DMi8 microscope (Leica Microsystems, Wetzlar, Germany) at 100x and 200x magnifications by two expert researchers who were blind to the source group. Both examiners reported the histological features of adenocarcinomas in five random fields from each section using a set of well-established criteria [37]. In case of a wide disagreement between both examiners, an independent expert histopathologist reexamined the sections. The captured images were analysed by the ImageJ software (https://imagej.nih.gov/ij/) to measure the surface areas $\left(\mu \mathrm{m}^{2}\right)$ of adenocarcinomas, as reported earlier $[21,37]$.

\section{Immunohistochemistry $(\mathrm{IHC})$}

All the primary antibodies were from Cell Signaling Technology Inc. (MA, USA). Rabbit monoclonal antibodies were used to detect CCND1 (\#55506), CDK inhibitor-1A (p21; \#37543) and mTOR (\#2983), whereas PI3K-p85a (\#13666) was detected by mouse monoclonal IgG antibodies. An avidin-biotin horseradish peroxidase technique was applied on $5 \mu \mathrm{m}$ tissue sections to detect the targeted proteins as previously described [38]. Briefly, BLOXALL ${ }^{\circledR}$ Solution (\#SP-6000-100; Vector Laboratories Inc., CA, USA) was used to block endogenous peroxidases. The primary antibodies (1:200 concentration for all) were added and the slides were incubated at $4^{\circ} \mathrm{C}$ overnight. In the following morning, ImmPRESS ${ }^{\circledR}$ HRP Horse Anti-mouse (\#MP-7402) or anti-rabbit (\#MP-7401) IgG Plus Polymer Peroxidase Kits were used as per the manufacturer's guidelines (Vector Laboratories Inc.). An identical protocol was applied for the negative control slides, but primary isotype mouse (\#sc-2025) or rabbit (\#sc-2027) IgG antibodies (Santa-Cruz Biotechnology Inc) were used to control for non-specific staining. The sections were counterstained with haematoxylin and examined with 20x objective on a Leica DMi8 microscope. Digital images were acquired from 10 different fields/section and the protein expression was analysed by ImageJ software (https://imagej.nih.gov/ij/) using the IHC Image Analysis Toolbox as previously reported [38,39].

\section{Terminal deoxynucleotidyl transferase-dUTP nick end labelling (TUNEL) Assay}

Cell apoptosis was detected in colonic tissues with a Click-iT ${ }^{\text {TM }}$ Plus TUNEL Assay (\#C10617; Thermo Fisher Scientific) and by using the manufacturer's protocol. The apoptotic bodies were co-localised with cleaved Casp-3 by applying a sequential protocol as reported earlier [40,41]. After completing the TUNEL protocol, anti-cleaved Casp-3 rabbit IgG monoclonal antibodies (\#9661; Cell Signaling Technology Inc.) were added at 1:400 concentration and the slides were incubated for $3 \mathrm{~h}$. Donkey anti-rabbit lgG antibodies tagged with Alexa Fluor ${ }^{\mathrm{TM}} 555$ (\#A-31572; Thermo Fisher Scientific) were then added for 30 min followed by DAPI counterstaining (\#D3571; Thermo Fisher Scientific). The slides were cover-slipped with a permanent fluorescence mounting medium (\#S3023; Dako, CA, USA) and observed on a Leica DMi8 microscope at 400× magnification. Images were acquired from 15 non-overlapping fields/section, and the apoptotic cells' numbers and cleaved Casp-3 staining intensity were measured by ImageJ software as previously reported $[39,42]$. 
The colonic tissue concentrations of survivin (\#SEC045Mu), cytochrome C (\#SEA594Mu), Akt1 (\#SEC231Mu), and PTEN (\#SEF822Mu) were measured by specific mouse ELISA kits (Cloud-Clone Corp.; TX, USA). The samples were processed in duplicate on an automated ELISA machine (Human Diagnostics) according to the manufacturer's protocols.

\section{Cell culture and treatment protocols}

The human SW480 primary and SW620 metastatic colon cancer cell lines were purchased from the American Type Culture Collection (ATCC; MA, USA). The SW480 and SW620 cells were cultured in DMEM that contained $10 \%$ FBS and $1 \%$ antibiotic-antimycotic solution. All cells were grown in a humified incubator at $37^{\circ} \mathrm{C}$ and $5 \% \mathrm{CO}_{2}$.

The 5-FU $(50 \mu \mathrm{M}), \mathrm{VD}_{3}(25 \mu \mathrm{M})$ and metformin $(39.8 \mathrm{mM})$ concentrations (IC50) were determined by the 3-(4,5-Dimethylthiazol-2-yl)-2,5-Diphenyltetrazolium Bromide (MTT) cytotoxicity assay at $24 \mathrm{~h}$ (Supplementary Figure 1). For cell cycle analysis, the SW480 $\left(2 \times 10^{5}\right)$ and SW620 $\left(3 \times 10^{5}\right)$ cells were seeded in 6-well plates for $24 \mathrm{~h}$ and then treated for $12 \mathrm{~h}$ with $5-\mathrm{FU}, \mathrm{VD}_{3}$ and/or metformin single, dual, and triple therapies, resulting in the following groups: untreated control (Ctr), 5-FU, $\mathrm{VD}_{3}$ and Met monotherapies, VF, MF and VM co-therapies, and VMF triple therapy. The $12 \mathrm{~h}$ time-point was applied to assure that any effects of combination therapies could be accurately analysed by cell cycle, apoptosis, gene, and protein expression techniques.

\section{Cell cycle analysis}

Cell cycle analysis was performed following the different treatment regimens in the SW480 and SW620 cells as previously described [21]. Briefly, cells were washed twice with PBS (500× $g$ for $5 \mathrm{~min}$ ) following trypsinisation and fixed in ice-cold $70 \%$ ethanol for $24 \mathrm{~h}$ at $4^{\circ} \mathrm{C}$. The cells were washed twice in PBS $(600 \times$ $g$ for $5 \mathrm{~min}$ ) and treated for $15 \mathrm{~min}$ with RNase A (20 $\mu \mathrm{g} / \mathrm{ml}$; \#12091021; Thermo Fisher), and $2 \mu \mathrm{g} / \mathrm{ml}$ propidium iodide (PI; \#P1304MP; Thermo Fisher) was added. Following staining, cell cycle analysis was immediately performed with a Novocyte 3000 flow cytometer (Agilent Technologies, CA, USA). The percentages of cells in different phases of cell cycle (Sub-G1, G0/G1, S, G2/M) were determined for 20,000 acquired events using the NovoExpress software cell cycle algorithm, and data are shown as mean $\pm S D(n=3)$.

Apoptosis assay

The Annexin V-FITC/PI Apoptosis Assay Kit (\#V13245; Thermo Fisher Scientific) was used according to the manufacturer's protocol. The cells were harvested after the different treatment protocols, washed twice with cold-ice PBS, and re-suspended in $100 \mu \mathrm{l}$ of $1 \times$ Annexin V (AV) binding buffer. For cell staining, the mixture of AV-FITC $(5 \mu \mathrm{l})$ and PI $(1 \mu \mathrm{l})$ were added to each $100 \mu \mathrm{l}$ of the SW480 and SW620 cell suspensions followed by incubation in dark for 15 minutes at room temperature. Subsequently, the AV 
binding buffer $(400 \mu \mathrm{l})$ was added, and the cells were placed on ice and immediately analysed using the NovoCyte 3000 flow cytometry. The experiments were processed in triplicate and the data represents percentage (mean $\pm \mathrm{SD}$ ) of the different apoptosis stages as follows: live (unstained), early ( $\mathrm{AV}+/ \mathrm{PI}-)$ and late apoptotic ( $\mathrm{AV}+/ \mathrm{PI}+)$, and dead (AV-/PI+) cells.

\section{Quantitative reverse-transcription polymerase chain reaction}

Following $12 \mathrm{~h}$ treatment with the different therapies, the SW480 and SW620 cells were trypsinised and washed in PBS. Total RNA was extracted by a PureLink ${ }^{T M}$ RNA Mini Kit (Thermo Fisher Scientific) and a high-capacity Reverse Transcription Kit was used for cDNA synthesis (\#4368814; Thermo Fisher Scientific). PCR was performed in triplicate wells/sample and consisted of 40 amplification cycles $\left(95^{\circ} \mathrm{C} / 15 \mathrm{~s}\right.$ and $\left.60^{\circ} \mathrm{C} / 1 \mathrm{~min}\right)$ that were processed with a QuantStudio ${ }^{\mathrm{Tm}} 3$ System. Each well contained $5 \mu \mathrm{l}$ SYBR Green, $3 \mu \mathrm{l}$ nuclease-free water, $5 \mathrm{pmol}(1 \mu \mathrm{l})$ of each set of primers (Supplementary Table 1) and 25 ng cDNA (1 $1 \mathrm{l})$. A minus-reverse transcription control from the prior RT step and a separate minustemplate PCR, in which the CDNA was replaced by nuclease-free water, were used as negative controls. The relative expression of CCND1, CCND3, p21, p27, BCL2, BAX, Cyto-C, Caspase-3, PIK3CA, PTEN, AKT1 and mTOR genes was calculated by the $2^{-\Delta \Delta \mathrm{Ct}}$ method [43].

\section{Western blot}

All primary antibodies were from Cell Signaling Technology Inc. (MA, USA). While mouse monoclonal IgG antibodies were used to detect CCND3 (\#2936), BCL2 (\#15071) and PI3K-p85a, rabbit monoclonal antibodies were used to detect CCND1, p21, p27 (\#3686), BAX (\#2772), Cyto-C (\#4272), cleaved Casp-3, PTEN (\#9188), Akt1 (\#75692) and mTOR, proteins by Western blotting. GAPDH loading control mouse monoclonal antibodies (\#MA5-15738-1MG; Thermo Fisher Scientific) were used for normalisation.

Briefly, total proteins were extracted from each cell pellet and $50 \mu \mathrm{g}$ total protein from each sample were loaded on gradient 4-20\% Mini-PROTEAN® TGX Stain-Free ${ }^{\text {TM }}$ SDS-PAGE gels (\#4568096; Bio-Rad Laboratories Inc.; CA, USA). The resolved proteins were then transferred to $0.2 \mu \mathrm{m}$ Trans-Blot ${ }^{\circledR}$ Turbo ${ }^{\mathrm{TM}}$ PVDF membranes using a Trans-Blot ${ }^{\circledR}$ Turbo ${ }^{\text {TM }}$ Transfer System (Bio-Rad Laboratories Inc). The membranes were blocked for 15 min with SuperBlock ${ }^{\text {TM }}$ T20 buffer (TBS-T; \#37543; Thermo Fisher Scientific), and incubated with primary antibodies (1:1000 for all antibodies) overnight at $4^{\circ} \mathrm{C}$. Next, the membranes were washed with TBS-T and incubated for $1 \mathrm{~h}$ with WestVision ${ }^{\text {TM }}$ secondary anti-mouse (\#WB-2000-8) or anti-rabbit (\#WB-1000-8) IgG antibodies (1:10,000) conjugated with peroxidase micropolymer (Vector Laboratories Inc.). The membranes were washed, and the signals developed by SignalFire ${ }^{\text {tw }}$ Plus ECL Reagent (\#12630; Cell Signaling Technology Inc.). The images were acquired by a ChemiDocTM XRS+ (Bio-Rad Laboratories Inc.) and the density of each protein band was quantified and then normalised against the densitometry of the GAPDH band by ImageJ software (https://imagej.nih.gov/ij/) as previously described [44]. Data are shown as mean \pm SD of three blots/cell line for each targeted protein. 


\section{Statistical Analysis}

SPSS statistical analysis software version 25 was used to analyse the data, and all variables were assessed for normality and homogeneity by the Kolmogorov and Smirnov's test and the Levene test, respectively. One-way analysis of variance (ANOVA) followed by Tukey's HSD or Games-Howell post-hoc tests were performed to compare between the study groups based on variance equality. Significance was considered when $P$ value was $<0.05$.

\section{Results}

\section{Effects of treatment regimens on CRC progression in mice}

Colonic tissues from the $\mathrm{NC}$ group demonstrated normal architecture by dissecting microscope as well as normal histology following H\&E staining (Figure 1A). By contrast, numerous MDF were seen in the PC group colons and co-existed with large numbers of gross and microscopic tumours. Bright-field microscope also revealed abundant colonic adenocarcinomas in the PC group that had large surface areas with poor to moderate differentiated histology (Figure 1).

The numbers of MDF (Figure 1B), dissecting microscope tumours (Figure 1D), total numbers of tumours (Figure 1E), and the surface areas of adenocarcinomas (Figure 1G) decreased significantly and equally in all monotherapy groups relative to the PC group. Moreover, the numbers of gross tumours were markedly lower in the 5-FU and Met groups, but not the $\mathrm{VD}_{3}$ group, compared with the PC mice. Nevertheless, the numbers of adenocarcinomas by light microscope were comparable between the PC and all monotherapy groups (Figure 1F).

All dual therapy protocols showed markedly lower numbers of MDF, gross and microscopic tumours, and adenocarcinomas alongside smaller adenocarcinoma surface areas compared with the $\mathrm{PC}, 5-\mathrm{FU}, \mathrm{VD}_{3}$ and Met groups. However, the anti-tumorigenic effects were significantly more pronounced in the MF group relative to the VF and VM co-therapy groups (Figure 1). On the other hand, the lowest numbers of MDF, gross tumours, and adenocarcinomas were detected in the triple therapy (VMF) group colons compared with the PC as well as all single and dual therapy groups (Figure 1).

\section{Effects of the different treatment protocols on cell cycle}

In vivo expression of CCND1 and p21

While the gene and protein expression of CCND1 increased significantly, the p21 mRNA and protein diminished, in the PC colonic tissues compared with the NC group (Figure 2). All monotherapies equally demonstrated marked declines in the mRNA and protein of CCND1 with concurrent significant increases in p21 gene and protein expression relative to the PC colonic tissues. Additional significant inhibitions in the CCND1 gene and protein expression alongside marked upregulations in the p21 gene and protein were detected in all co-therapy groups relative to the monotherapy groups (Figure 2). Moreover, the 
CCND1 gene and protein expression were significantly lower and coincided with markedly higher p21 mRNA and protein in the MF group than the VF and VM co-therapies (Figure 2). Nonetheless, the highest p21 gene and protein expression together with the lowest levels of CCND1 mRNA and protein were observed in the VMF group compared with the PC, 5-FU, VD 3 , Met, VF, MF, and VM groups (Figure 2).

In vitro cell cycle arrest and expression of cell cycle regulatory molecules

Single treatment with 5-FU and metformin equally and markedly augmented the SW480 cell counts in the Sub-G1 phase (2-fold; for both), the highest increases were seen in the VM group (2.4-fold), compared with non-treated cells (Figure 3A). Alternatively, all monotherapies showed equal increases in the SW620 cell numbers in the Sub-G1 phase (1.3-fold for all), whilst the MF co-therapy revealed the maximal increase (2.8-fold) relative to control cells (Figure 3B). All treatments, except $\mathrm{VD}_{3}$ monotherapy, markedly increased the SW480 cell numbers in the G0/G1-phase ( 1.5-fold) compared with untreated cells, and the results were comparable between the different therapies (Figure $3 \mathrm{~A}$ ). Although all treatments were also associated with G0/G1-phase arrest in the SW620 cells, metformin monotherapy showed the maximal significant increase relative to non-treated cells (1.6-fold; Figure 3B).

All monotherapies also revealed marked decreases in CCND1 and CCND3 alongside increases in the p21 and p27 genes (Supplementary Figure 2) and proteins (Figure 4) relative to untreated SW480, and SW620 cells, and the effects of metformin-alone were more prominent in both cell lines. The dual therapies further downregulated CCND1 and CCND3, whilst promoting p21 and p27, genes and proteins compared with all monotherapies in both cell lines, and the MF approach was markedly more effective relative to the other dual therapies. However, the lowest CCND1 and CCND3 alongside the highest upregulations in p21 and p27 genes (Supplementary Figure 2) and proteins (Figure 4) were detected with the triple therapy in both cell lines compared with untreated cells as well as with the other therapeutic approaches.

\section{Effects of the different treatment protocols on cell death and apoptosis markers}

\section{Colonic cell apoptosis and apoptosis markers in vivo}

In the NC group colonic tissues, apoptotic bodies and cleaved Casp-3 protein were mainly detected in glandular luminal and cryptic epithelium together with stomal cells (Figure 5A). The numbers of apoptotic bodies, cleaved Casp-3 protein, colonic tissue levels of Cyto-C protein, and apoptosis index decreased substantially and concurred with a marked increase in survivin protein relative to the NC group (Figure 5). All monotherapies revealed marked declines in colonic tissue survivin concentrations alongside increases in colonic tissue Cyto-C levels with higher apoptosis index and Casp-3 protein expression compared with the PC group. While the expression of Casp-3 protein and apoptosis index were significantly higher in the 5 -FU group than the $\mathrm{VD}_{3}$ and Met groups (Figure $5 \mathrm{~B}$ ), colonic survivin and Cyto-C tissue concentrations were similar between all monotherapies (Figure $5 \mathrm{C}$ ). Moreover, cleaved Casp-3 and apoptosis index were markedly higher in the Met group than the $\mathrm{VD}_{3}$ group (Figure $5 \mathrm{~B}$ ). 
Although colonic Cyto-C, cleaved Casp-3 and apoptosis index were markedly higher in all co-therapy groups and coincided with significant reductions in survivin relative to the PC and monotherapy groups, the results were significantly stronger in the MF group than the VD and VM groups (Figure 5). The VMF group, on the other hand, demonstrated the maximal cyto-C concentrations, the highest apoptosis index and cleaved Casp-3 expression, and the lowest survivin levels compared with the PC, all monotherapies, and dual therapy groups (Figure 5).

In vitro cell apoptosis and expression of apoptosis markers

All treatment protocols significantly reduced the numbers of living cells in the cell lines used relative to untreated cells, except for $\mathrm{VD}_{3}$ single treatment that showed comparable results to the $\mathrm{SW} 620$ control cells (Figure 6). In the SW480 cells, 5-FU with metformin dual treatment displayed the highest rate of cell death that was depicted with marked increases in the numbers of cells in early and late apoptosis relative to all therapeutic protocols (Figure 6A). On the other hand, the minimal numbers of viable SW620 cells were detected in the VMF group that concord with the maximal increases in the percentages of early and late apoptotic cells compared with all groups (Figure 6B).

The monotherapies also revealed marked decreases in BCL2 along with increases in BAX, Cyto-C and Casp-3 genes (Supplementary Figure 3) and proteins (Figure 7) compared with untreated SW480 and SW620 cells, and the metformin single therapy was more prominent relative to all monotherapy groups. In contrast, and although the dual therapies also reduced the expression of BCL2, whereas increased BAX, Cyto-C and Casp-3, genes and proteins in both cell lines, the MF co-therapy was the most efficient compared with the other dual therapies. Moreover, the triple therapy regimen showed the best downregulation in the mRNAs (Supplementary Figure 3) and proteins (Figure 7) of BCL2 along with the maximal increases in BAX, Cyto-C \& Casp-3 relative to all therapies in the tested cell lines.

\section{Effects of the different treatment protocols on the expression of PI3K/Akt/mTOR oncogenic pathway}

\section{Protein expression of PI3K/Akt/mTOR in colonic tissues}

The PI3K-p85a and mTOR protein expression alongside tissue levels of Akt1 protein increased significantly, whereas PTEN protein concentrations declined, in the PC colonic tissues relative to the NC group (Figure 8). Although 5-FU monotherapy significantly reduced the expression of PI3K-p85a protein compared with the PC group, the levels of Akt1, PTEN and mTOR proteins were comparable between both groups. Single treatment with metformin and $\mathrm{VD}_{3}$ also showed substantial reductions in PI3K-p85a and Akt1 alongside increases in PTEN proteins compared with the PC group. However, metformin monotherapy showed significantly more effective modulatory effects on the targeted proteins relative to the 5-FU and $\mathrm{VD}_{3}$ groups (Figure 8). All dual therapy protocols showed further significant declines in PI3Kp85a, Akt1 and mTOR with concurrent increases in PTEN proteins with compared with all monotherapy groups, and the MF group was significantly more effective than the other co-therapy groups. However, the triple therapy regimen showed the lowest PI3K-p85a, Akt1 and mTOR proteins alongside the highest

Page $11 / 32$ 
concentrations of PTEN protein compared with the PC group and all single and dual treatment protocols (Figure 8).

In vitro gene and protein expression of the PI3K/Akt/mTOR oncogenic pathway

The monotherapy groups disclosed significant inhibitions in the PI3K-p85a, Akt1, and mTOR genes (Supplementary Figure 4) and proteins (Figure 9) alongside increases in PTEN mRNA and protein in the SW480 cells, and metformin monotherapy showed the most significant modulations compared with untreated cells and the other single therapies. In the SW620 metastatic colon cancer cells, however, 5-FU and $\mathrm{VD}_{3}$ monotherapies showed negligible effects on the targeted genes and proteins, whereas metformin exhibited marked modulations at the transcriptional and translational levels. Although the MF co-therapy approach showed the most prominent decreases in the genes (Supplementary Figure 4) and proteins (Figure 9) of PI3K-p85a, Akt1, and mTOR with concurrent increases in PTEN mRNA and protein relative to all dual therapy protocols, the maximal significant modulatory effects in both cell lines were observed with the triple therapy.

\section{Discussion}

This study compared the anti-cancer effects of single, dual, and triple treatments with 5-FU, active $\mathrm{VD}_{3}$ and/or metformin against CRC in vivo and in vitro. The gold standard chemotherapy used for treating $\mathrm{CRC}, 5-\mathrm{FU}$, provokes cell cycle arrest at the S-phase by inhibiting thymidylate synthase, an enzyme required for DNA replication [8,9]. Others have also shown arrest at the G0/G1-phase of cell cycle following 5-FU single therapy in the HCT116 and SW620 CRC cell lines $[45,46]$. Concurrently, 5-FU halts the progression of colon cancer by modulating many pro-apoptotic pathways [21,47]. However, cancerous cells often resist 5-FU actions through several mechanisms, including increasing energy supply by switching to aerobic glycolysis to sustain survival, a phenomenon known as the Warburg effect [48]. Under this theme, the PI3K/Akt/mTOR signalling pathway is a central regulator of cell metabolism and survival, and during colon carcinogenesis the pathway is abnormally hyperactivated, whilst the expression of its endogenous inhibitor, PTEN, declines $[16,47,49]$. The aberrant activation of the $\mathrm{PI} 3 \mathrm{~K} / \mathrm{Akt} / \mathrm{mTOR}$ network suppresses apoptosis by upregulating the cell survival molecule, BCL2, that inhibits $B A X$ and subsequently the release of Cyto-C from mitochondria $[16,49,50]$. The dysregulation in the PI3K/PTEN/Akt/mTOR pathway also promotes the metabolic shifting to glycolysis, thus reducing the efficacy of 5-FU by decreasing its absorption, due to acidification of the tumour microenvironment as well as hindering cell apoptosis $[16,49,50]$.

Herein, 5-FU monotherapy moderately decreased the numbers of MDF and tumours, but not adenocarcinomas, compared with the PC mice. Single treatment with 5-FU also induced cell cycle arrest at the G0/G1-phase in the SW480 and SW620 cells and was associated with marked increases in the numbers of apoptotic cells, both in vivo and in vitro. Moreover, 5-FU monotherapy significantly reduced the cell cycle inducing (CCND1/CCND3) and survival (survivin/BCL2) markers alongside promoted the cell cycle inhibitory (p21/p27) and pro-apoptotic (BAX/Cyto-C/Casp-3) molecules at the gene and protein 
levels in treated mice as well as in SW480 cells. However, the cytotoxic drug showed limited efficacy on the expression of cell cycle and apoptosis regulatory molecules in the SW620 metastatic cells. Additionally, 5-FU single therapy showed negligible effects on the gene and protein expression of PI3K, Akt, PTEN, and mTOR in vivo and in vitro. Our results agree with many studies that have shown cell cycle arrest and apoptosis in colon cancer cells with 5-FU single treatment [8,9,21,45-47], and further support the notion that resistance to chemotherapy could, at least in part, be related to a limited efficacy in modulating the PI3K/PTEN/Akt/mTOR pathway by 5-FU monotherapy $[16,48,49]$.

Chemoresistance is a major clinical problem during the treatment of CRC, especially during the late stages of malignancy, and the quest for developing alternative and/or complementary therapies has therefore been the target of many studies $[10,11]$. In this context, the overall and cancer-specific survival rates were significantly higher in diabetic CRC patients and who were using metformin relative to nonusers [51,52]. Other in vitro studies have likewise reported persuasive anti-tumorigenic effects for metformin single therapy that were depicted by marked suppression of cell cycle progression, induction of apoptosis, and inhibition of the PI3K/Akt/mTOR molecules [24-28]. Similarly, several epidemiological studies disclosed inverse links between serum VD levels with the prevalence of $C R C[18,19]$. Active $V_{3}$ treatment also reduced cell proliferation, altered mitochondrial membrane potential, inhibited the $\mathrm{PI} 3 \mathrm{~K} / \mathrm{Akt} / \mathrm{mTOR}$ pathway and suppressed glycolysis alongside inducing cell cycle arrest and apoptosis in several human colon cancer cell lines [20-23]. Moreover, the chemopreventive actions of $\mathrm{VD}_{3}$ and metformin against CRC were compared by only two studies, and their results exhibited equal efficacies for both drugs in vitro [32] and in vivo [33], whereas their combination showed boosted anti-tumorigenic actions. Additionally, others have revealed enhanced anti-cancer effects against $C R C$ by adding $\mathrm{VD}_{3}$ $[21,29]$ or metformin $[30,31]$ with 5 -FU. However, none of the earlier studies compared the therapeutic efficacies between the metformin with $\mathrm{VD}_{3}$, and/or 5-FU, dual and triple therapies against CRC progression.

This study revealed cell cycle arrest with increased p21 and p27 alongside decreased CCND1 and CCND3 genes and proteins following in vivo and in vitro treatment with $\mathrm{VD}_{3}$ and metformin monotherapies, confirming many reports that proclaimed suppression of cell cycle by both agents [20,21,24-28]. However, in vivo, and in vitro metformin single treatment also showed higher cell death, increased gene, and protein expression of apoptosis markers and PTEN, and downregulations of the PI3K/Akt/mTOR molecules, whereas the $\mathrm{VD}_{3}$ monotherapy effects were weaker. While all dual therapy protocols disclosed enhanced modulations of the PI3K/PTEN/Akt/mTOR pathway, higher numbers of apoptotic cells, and boosted expression of pro-apoptotic molecules compared with all monotherapies, the effects were markedly more pronounced with Met/5-FU co-therapy relative to the $\mathrm{VD}_{3} / 5-\mathrm{FU}$ and Met/ $\mathrm{VD}_{3}$ groups, both in vivo and in vitro. To the best of our knowledge, this study is also the first to demonstrated enhanced anti-tumorigenic effects for $\mathrm{VD}_{3} /$ Met/5-FU triple therapy in the treatment of colon cancer. Our data revealed that the VMF group had the highest expression of PTEN along with the cell cycle inhibitory and pro-apoptotic molecules that coincided with the lowest levels of CCND1, CCND3, BCL2, PI3K, Akt, and mTOR compared with all therapeutic regimens in animals and the colon cancer cell lines used.

Page $13 / 32$ 
The current data suggest that metformin monotherapy is superior to $\mathrm{VD}_{3}$ single therapy, as well as metformin appears to be a better chemosensitizer to 5 -FU cytotoxicity than $\mathrm{VD}_{3}$ for the treatment of $\mathrm{CRC}$. A plausible explication for the disagreement between the present and the earlier in vivo and in vitro studies on the $\mathrm{VD}_{3}$ anti-cancer efficacy could be related to the relatively shorter treatment durations (4 weeks \& $12 \mathrm{~h}$, respectively) in our study compared with longer timepoints ( $\geq 8$ weeks \& $\geq 24 \mathrm{~h}$, respectively) in the prior reports $[21,32,53,54]$. We also hypothesise that the superiority of metformin proapoptotic effects over $\mathrm{VD}_{3}$, with and without 5 - $\mathrm{FU}$, could involve better attenuations of the $\mathrm{PI} 3 \mathrm{~K} / \mathrm{Akt} / \mathrm{mTOR}$ oncogenic molecules by inducing the expression of the tumour suppressor protein, PTEN, thus promoting oxidative metabolism and subsequently mitochondrial-induced apoptosis in neoplastic cells [24-28]. Moreover, the triple therapy in the present study showed the best tumoricidal actions against CRC and could represent the best strategy for treating early and late stages of colon neoplasia. However, more studies that apply several timepoints (e.g., 12, 24, 48 and 72h) of VD 3 treatment as well as measure the markers of glycolysis and oxidative phosphorylation following the different therapeutic protocols are needed to confirm our suggestions.

There are several drawbacks to the present study. Firstly, we only measured the expression of PTEN, and other negative regulators of the PI3K/Akt/mTOR pathway (e.g., AMPK, GSK-3 $\beta$ ) should be included in future studies. Moreover, we only applied concomitant combination protocols and additional studies that use consecutive combinatory regimens (e.g., Met followed by $\mathrm{VD}_{3}$ and/or $5-\mathrm{FU}$ ) are needed to precisely identify the most effective approach for CRC treatment. The expression of enzymes involved in oxidative metabolism alongside the markers of glycolysis should also be measured in future studies to corroborate the present findings.

In conclusion, metformin single therapy was superior in its anticancer effects to active $\mathrm{VD}_{3}$, showing higher expression of p21, p27, PTEN, BAX, Cyto-C, and Casp-3, inhibitions in CCND1, CCND3, BCL2 and the PI3K/Akt/mTOR network, alongside higher rates of apoptosis, both in vivo and in vitro. Although all dual therapy protocols revealed enhanced modulations of the PI3K/PTEN/Akt/mTOR pathway, alongside higher expression of the cell cycle inhibitors and pro-apoptotic molecules than the monotherapies, the Met/5-FU co-therapy was better relative to the other dual therapies. In contrast, the triple therapy regimen exhibited the best anti-cancer effects related to cell cycle arrest and apoptosis compared with the single and dual protocols, possibly by boosted attenuations of the PI3K/Akt/mTOR oncogenic pathway. Nevertheless, more studies are needed to measure the tumoricidal effects of $\mathrm{VD}_{3}$ and/or metformin concomitant and sequential therapies, with and without 5-FU, using multiple time-points, as well as to measure the metabolic markers of glycolysis and oxidative phosphorylation, to accurately determine their therapeutic values against CRC.

\section{Declarations}

\section{Funding}


This work was supported by the Deanship of Scientific Research in Umm Al-Qura University [Grant Code: 19-MED-1-01-0022]. The funding organisation was not involved in the design of the study; the collection, analysis, and interpretation of data; writing the report; and did not impose any restrictions regarding the publication of the report.

\section{Conflicts of interest/Competing interests}

The authors have no relevant financial or non-financial interests to disclose.

\section{Data availability}

All data generated or analysed during this study are included in this published article [and its supplementary information files].

\section{Code availability}

Not applicable.

\section{Ethics approval}

Ethical approval was obtained from the Committee for the Care and Use of Laboratory Animals at Umm Al-Qura University (AMSEC 19/05-10-20).

\section{Consent to participate}

Not applicable.

\section{Consent for publication}

Not applicable.

\section{Authors' contributions}

Conceptualization: RA, BR \& AA; Methodology: AA, JA, MEB, AHA, M Alhadrami, SI, MEA \& SYE; Formal analysis: RA, BR, AA, MZE, MEB \& AHA; Investigation: AA, JA, SI, M Althubiti, HA \& MEA; Funding acquisition: RA, M Althubiti, HA \& MMG; Resources \& Project administration: RA; M Althubiti, HA \& MMG; Data curation: BR; AA, MZE, MEB \& AHA; Writing-original draft: RA \& BR; Supervision: RA, BA \& AA. All authors have read and approved the manuscript.

\section{References}

1. Sung H, Ferlay J, Siegel RL, Laversanne M, Soerjomataram I, Jemal A, et al. Global Cancer Statistics 2020: GLOBOCAN Estimates of Incidence and Mortality Worldwide for 36 Cancers in 185 Countries. Cancer J Clin. 2021;71:209-49. doi 10.3322/caac.21660. 
2. Bray F, Ferlay J, Soerjomataram I, Siegel RL, Torre LA, Jemal A. Global cancer statistics 2018: GLOBOCAN estimates of incidence and mortality worldwide for 36 cancers in 185 countries. Cancer J Clin. 2018;68:394-424. doi 10.3322/caac.21492.

3. Li Y, Wei J, Xu C, Zhao Z, You T. Prognostic significance of cyclin D1 expression in colorectal cancer: a meta-analysis of observational studies. PloS one. 2014;9:e94508. doi 10.1371/journal.pone.0094508.

4. Jakubowska K, Pryczynicz A, Dymicka-Piekarska V, Famulski W, Guzińska-Ustymowicz K. Immunohistochemical expression and serum level of survivin protein in colorectal cancer patients. Oncology letters. 2016;12:3591-7. doi 10.3892/ol.2016.5075.

5. Al-Maghrabi J, Al-Ahwal M, Buhmeida A, Syrjänen K, Sibyani A, Emam E, et al. Expression of cell cycle regulators p21 and p27 as predictors of disease outcome in colorectal carcinoma. Journal of gastrointestinal cancer. 2012;43:279-87. doi 10.1007/s12029-011-9292-y.

6. Simpson KL, Cawthorne C, Zhou C, Hodgkinson CL, Walker MJ, Trapani F, et al. A caspase-3 'deathswitch' in colorectal cancer cells for induced and synchronous tumor apoptosis in vitro and in vivo facilitates the development of minimally invasive cell death biomarkers. Cell death disease. 2013;4:e613. doi 10.1038/cddis.2013.137.

7. Oh HJ, Bae JM, Wen X, Jung S, Kim Y, Kim KJ, et al. p53 expression status is associated with cancerspecific survival in stage III and high-risk stage II colorectal cancer patients treated with oxaliplatinbased adjuvant chemotherapy. British journal of cancer. 2019;120:797-805. doi 10.1038/s41416019-0429-2.

8. Can G, Akpinar B, Baran Y, Zhivotovsky B, Olsson M. 5-Fluorouracil signaling through a calciumcalmodulin-dependent pathway is required for p53 activation and apoptosis in colon carcinoma cells. Oncogene. 2013;32:4529-38. doi 10.1038/onc.2012.467.

9. Akpinar B, Bracht EV, Reijnders D, Safarikova B, Jelinkova I, Grandien A, et al. 5-Fluorouracil-induced RNA stress engages a TRAIL-DISC-dependent apoptosis axis facilitated by p53. Oncotarget. 2015;6:43679-97. doi 10.18632/oncotarget.6030.

10. Satapathy SR, Sjölander A. Cysteinyl leukotriene receptor 1 promotes 5 -fluorouracil resistance and resistance-derived stemness in colon cancer cells. Cancer letters. 2020;488:50-62. doi 10.1016/j.canlet.2020.05.023.

11. Koulis C, Yap R, Engel R, Jardé T, Wilkins S, Solon G, et al Personalized Medicine-Current and Emerging Predictive and Prognostic Biomarkers in Colorectal Cancer. Cancers 2020;12: doi 10.3390/cancers12040812.

12. Johnson SM, Gulhati P, Rampy BA, Han Y, Rychahou PG, Doan HQ, et al. Novel expression patterns of $\mathrm{PI3K} / \mathrm{Akt} / \mathrm{mTOR}$ signaling pathway components in colorectal cancer. J Am Coll Surg. 2010;210:76776. doi 10.1016/j.jamcollsurg.2009.12.008. 76-8.

13. Taniguchi CM, Winnay J, Kondo T, Bronson RT, Guimaraes AR, Alemán JO, et al. The phosphoinositide 3-kinase regulatory subunit p85alpha can exert tumor suppressor properties 
through negative regulation of growth factor signaling. Cancer research. 2010;70:5305-15. doi 10.1158/0008-5472.can-09-3399.

14. Francipane MG, Lagasse E. mTOR pathway in colorectal cancer: an update. Oncotarget. 2014;5:4966. doi 10.18632/oncotarget.1548.

15. Reita D, Bour C, Benbrika R, Groh A, Pencreach E, Guérin E, et al Synergistic Anti-Tumor Effect of mTOR Inhibitors with Irinotecan on Colon Cancer Cells. Cancers 2019;11: doi 10.3390/cancers11101581.

16. Yang J, Nie J, Ma X, Wei Y, Peng Y, Wei X. Targeting PI3K in cancer: mechanisms and advances in clinical trials. Mol Cancer. 2019;18:26. doi 10.1186/s12943-019-0954-x.

17. Narayanankutty A. PI3K/ Akt/ mTOR Pathway as a Therapeutic Target for Colorectal Cancer: A Review of Preclinical and Clinical Evidence. Curr Drug Targets. 2019;20:1217-26. doi $10.2174 / 1389450120666190618123846$.

18. McCullough ML, Zoltick ES, Weinstein SJ, Fedirko V, Wang M, Cook NR, et al. Circulating Vitamin D and Colorectal Cancer Risk: An International Pooling Project of 17 Cohorts. J Natl Cancer Inst. 2019;111:158-69. doi 10.1093/jnci/djy087.

19. Liang Y, Jiang L, Chi X, Hochwald S, Qiu F, Luo Y, et al. The association of serum vitamin D-binding protein and 25-hydroxyvitamin $D$ in pre-operative and post-operative colorectal cancer. Journal of clinical laboratory analysis. 2020;34:e23154. doi 10.1002/jcla.23154.

20. Liaudat AC, BohI LP, Tolosa de Talamoni NG, Maletto B, Pistoresi-Palencia MC, Picotto G. Oxidative stress, cell cycle arrest and differentiation contribute toward the antiproliferative action of BSO and calcitriol on Caco-2 cells. Anti-cancer drugs. 2014;25:810-8. doi 10.1097/cad.0000000000000109.

21. Aslam A, Ahmad J, Baghdadi MA, Idris S, Almaimani R, Alsaegh A, et al. Chemopreventive effects of vitamin $\mathrm{D}(3)$ and its analogue, paricalcitol, in combination with 5 -fluorouracil against colorectal cancer: The role of calcium signalling molecules. Biochimica et biophysica acta Molecular basis of disease. 2021;1867:166040. doi 10.1016/j.bbadis.2020.166040.

22. Zuo S, Wu L, Wang Y, Yuan X. Long Non-coding RNA MEG3 Activated by Vitamin D Suppresses Glycolysis in Colorectal Cancer via Promoting c-Myc Degradation. Frontiers in oncology. 2020;10:274. doi 10.3389/fonc.2020.00274.

23. Huang CY, Weng YT, Li PC, Hsieh NT, Li Cl, Liu HS, et al Calcitriol Suppresses Warburg Effect and Cell Growth in Human Colorectal Cancer Cells. Life (Basel Switzerland) 2021;11: doi 10.3390/life11090963.

24. Amable G, Martínez-León E, Picco ME, Di Siervi N, Davio C, Rozengurt E, et al. Metformin inhibits $\beta$ catenin phosphorylation on Ser-552 through an AMPK/PI3K/Akt pathway in colorectal cancer cells. Int J Biochem Cell Biol. 2019;112:88-94. doi 10.1016/j.biocel.2019.05.004.

25. Guo J, Li Y, Duan H, Yuan L. Metformin Suppresses the Proliferation and Promotes the Apoptosis of Colon Cancer Cells Through Inhibiting the Expression of Long Noncoding RNA-UCA1. Onco Targets Ther. 2020;13:4169-81. doi 10.2147/ott.s245091. 
26. Liu C, Liu Q, Yan A, Chang H, Ding Y, Tao J, et al. Metformin revert insulin-induced oxaliplatin resistance by activating mitochondrial apoptosis pathway in human colon cancer HCT116 cells. Cancer medicine. 2020;9:3875-84. doi 10.1002/cam4.3029.

27. Khodaei F, Hosseini SM, Omidi M, Hosseini SF, Rezaei M. Cytotoxicity of metformin against HT29 colon cancer cells contributes to mitochondrial Sirt3 upregulation. J Biochem Mol Toxicol. 2021;35:e22662. doi 10.1002/jbt.22662.

28. Marciano O, Mehazri L, Shpungin S, Varvak A, Zacksenhaus E, Nir U. Fer and FerT Govern Mitochondrial Susceptibility to Metformin and Hypoxic Stress in Colon and Lung Carcinoma Cells. Cells 2021;10: doi 10.3390/cells10010097.

29. Refaat B, El-Shemi AG, Kensara OA, Mohamed AM, Idris S, Ahmad J, et al. Vitamin D3 enhances the tumouricidal effects of 5-Fluorouracil through multipathway mechanisms in azoxymethane rat model of colon cancer. Journal of experimental clinical cancer research: CR. 2015;34:71. doi 10.1186/s13046-015-0187-9.

30. Sang J, Tang R, Yang M, Sun Q. Metformin Inhibited Proliferation and Metastasis of Colorectal Cancer and presented a Synergistic Effect on 5-FU. BioMed research international. 2020;2020:9312149. doi 10.1155/2020/9312149.

31. Fernandes JM, Jandrey EHF, Koyama FC, Leite KRM, Camargo AA, Costa ÉT, et al. Metformin as an Alternative Radiosensitizing Agent to 5-Fluorouracil During Neoadjuvant Treatment for Rectal Cancer. Dis Colon Rectum. 2020;63:918-26. doi 10.1097/dcr.0000000000001626.

32. Abu El Maaty MA, Strassburger W, Qaiser T, Dabiri Y, Wölfl S. Differences in p53 status significantly influence the cellular response and cell survival to 1,25-dihydroxyvitamin D3-metformin cotreatment in colorectal cancer cells. Molecular carcinogenesis. 2017;56:2486-98. doi 10.1002/mc.22696.

33. Li W, Wang QL, Liu X, Dong SH, Li HX, Li CY, et al. Combined use of vitamin D3 and metformin exhibits synergistic chemopreventive effects on colorectal neoplasia in rats and mice. Cancer Prev Res (Phila). 2015;8:139-48. doi 10.1158/1940-6207.capr-14-0128.

34. Taheri S, Asim M, Al Malki H, Fituri O, Suthanthiran M, August P. Intervention using vitamin D for elevated urinary albumin in type 2 diabetes mellitus (IDEAL-2 Study): study protocol for a randomised controlled trial. Trials. 2018;19:230. doi 10.1186/s13063-018-2616-5.

35. Gabriel R, Boukichou Abdelkader N, Acosta T, Gilis-Januszewska A, Gómez-Huelgas R, Makrilakis K, et al. Early prevention of diabetes microvascular complications in people with hyperglycaemia in Europe. ePREDICE randomized trial. Study protocol, recruitment and selected baseline data. PloS one. 2020;15:e0231196. doi 10.1371/journal.pone.0231196.

36. Nair AB, Jacob S. A simple practice guide for dose conversion between animals and human. Journal of basic clinical pharmacy. 2016;7:27-31. doi 10.4103/0976-0105.177703.

37. Refaat B, El-Shemi AG, Mohamed AM, Kensara OA, Ahmad J, Idris S. Activins and their related proteins in colon carcinogenesis: insights from early and advanced azoxymethane rat models of colon cancer. BMC Cancer. 2016;16:879. doi 10.1186/s12885-016-2914-9. 
38. Refaat B, Zekri J, Aslam A, Ahmad J, Baghdadi MA, Meliti A, et al Profiling Activins and Follistatin in Colorectal Cancer According to Clinical Stage, Tumour Sidedness and Smad4 Status. Pathology Oncology Research 2021;27: doi 10.3389/pore.2021.1610032.

39. Refaat B, Abdelghany AH, BaSalamah MA, El-Boshy M, Ahmad J, Idris S. Acute and Chronic Iron Overloading Differentially Modulates the Expression of Cellular Iron-homeostatic Molecules in Normal Rat Kidney. The journal of histochemistry and cytochemistry: official journal of the

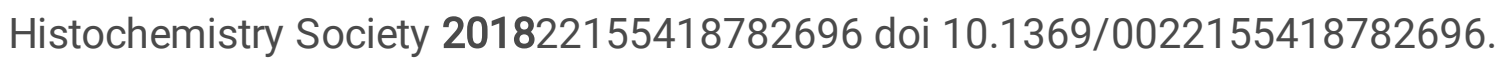

40. El-Boshy M, Alsaegh A, Qasem AH, Sindi RA, Abdelghany AH, Gadalla H, et al. Enhanced renoprotective actions of Paricalcitol and omega-3 fatty acids co-therapy against diabetic nephropathy in rat. J Adv Res. 2021. doi https://doi.org/10.1016/j.jare.2021.08.010.

41. Refaat B, Abdelghany AH, Ahmad J, Abdalla OM, Elshopakey GE, Idris S, et al. Vitamin D3 enhances the effects of omega-3 oils against metabolic dysfunction-associated fatty liver disease in rat. BioFactors;n/a: doi https://doi.org/10.1002/biof.1804.

42. Patntirapong S, Chanruangvanit C, Lavanrattanakul K, Satravaha Y. Assessment of bisphosphonate treated-osteoblast behaviors by conventional assays and a simple digital image analysis. Acta histochemica. 2021;123:151659. doi 10.1016/j.acthis.2020.151659.

43. Livak KJ, Schmittgen TD. Analysis of relative gene expression data using real-time quantitative PCR and the 2(-Delta Delta C(T)) Method. Methods (San Diego. Calif). 2001;25:402-8. doi 10.1006/meth.2001.1262.

44. Almaimani RA, Almasmoum H, Ghaith MM, El-Boshy M, Idris S, Ahmad J, et al. Enhanced remedial effects for vitamin D3 and calcium co-supplementation against pre-existing lead nephrotoxicity in mice: The roles of renal calcium homeostatic molecules. Biochimica et biophysica acta Molecular basis of disease. 2019;1865:512-24. doi 10.1016/j.bbadis.2018.11.023.

45. Matuo R, Sousa FG, Escargueil AE, Grivicich I, Garcia-Santos D, Chies JA, et al. 5-Fluorouracil and its active metabolite FdUMP cause DNA damage in human SW620 colon adenocarcinoma cell line. Journal of applied toxicology: JAT. 2009;29:308-16. doi 10.1002/jat.1411.

46. Kang YH, Lee JS, Lee NH, Kim SH, Seo CS, Son CG. Coptidis Rhizoma Extract Reverses 5-Fluorouracil Resistance in HCT116 Human Colorectal Cancer Cells via Modulation of Thymidylate Synthase. Molecules 2021;26: doi 10.3390/molecules26071856.

47. Kim EJ, Kang GJ, Kang JI, Boo HJ, Hyun JW, Koh YS, et al. Over-activation of AKT signaling leading to 5-Fluorouracil resistance in SNU-C5/5-FU cells. Oncotarget. 2018;9:19911-28. doi 10.18632/oncotarget.24952.

48. Liu C, Jin Y, Fan Z. The Mechanism of Warburg Effect-Induced Chemoresistance in Cancer. Frontiers in oncology. 2021;11:698023. doi 10.3389/fonc.2021.698023.

49. Liu R, Chen Y, Liu G, Li C, Song Y, Cao Z, et al. PI3K/AKT pathway as a key link modulates the multidrug resistance of cancers. Cell death disease. 2020;11:797. doi 10.1038/s41419-020-02998-6.

50. Rascio F, Spadaccino F, Rocchetti MT, Castellano G, Stallone G, Netti GS, et al The Pathogenic Role of PI3K/AKT Pathway in Cancer Onset and Drug Resistance: An Updated Review Cancers 2021;13: doi 
10.3390/cancers13163949.

51. Meng F, Song L, Wang W. Metformin Improves Overall Survival of Colorectal Cancer Patients with Diabetes: A Meta-Analysis. J Diabetes Res. 2017;2017:5063239. doi 10.1155/2017/5063239.

52. Cheng Y, Chen Y, Zhou C, Shen L, Tu F, Xu J, et al. For colorectal cancer patients with type II diabetes, could metformin improve the survival rate? A meta-analysis. Clinics research in hepatology gastroenterology. 2020;44:73-81. doi 10.1016/j.clinre.2019.06.009.

53. Zhang YG, Lu R, Wu S, Chatterjee I, Zhou D, Xia Y, et al. Vitamin D Receptor Protects Against Dysbiosis and Tumorigenesis via the JAK/STAT Pathway in Intestine. Cellular molecular gastroenterology hepatology. 2020. doi 10.1016/j.jcmgh.2020.05.010.

54. Kotlarz A, Przybyszewska M, Swoboda P, Neska J, Miłoszewska J, Grygorowicz MA, et al. Imatinib inhibits the regrowth of human colon cancer cells after treatment with 5-FU and cooperates with vitamin D analogue PRI-2191 in the downregulation of expression of stemness-related genes in 5-FU refractory cells. J Steroid Biochem Mol Biol. 2019;189:48-62. doi 10.1016/j.jsbmb.2019.02.003.

\section{Figures}

\section{Figure 1}

(A) Mouse colon mucosa from all the study groups by dissecting microscope ( $n=10$ mice/group; $\times 20$ magnification; red arrow $=$ tumours $\&$ yellow arrow $=$ mucin depleted foci [MDF]) alongside colonic tissue sections from all groups by H\&E stain ( $n=10$ mice/group; $\times 200$ magnification; scale bar $=15 \mu \mathrm{m}$ ).

Furthermore, the numbers of (B) MDF, (C) gross tumours, (D) microscopic tumours, (E) total tumours and $(F)$ adenocarcinomas alongside $(G)$ the adenocarcinomas' surfaces areas are shown as graph bars $(n=$ 10 mice/group; data was analysed by ANOVA followed by Games-Howell post-hoc test and is shown as mean \pm SD; $a=P<0.05$ compared with the NC group; $b=P<0.05$ compared with the $P C$ group; $c=P<$ 0.05 compared with 5-FU monotherapy; $\mathrm{d}=\mathrm{P}<0.05$ compared $\mathrm{VD}_{3}$ monotherapy, $\mathrm{e}=\mathrm{P}<0.05$ compared with Met monotherapy; $f=P<0.05$ compared with VF dual therapy; $g=P<0.05$ compared with MF dual therapy and $\mathrm{h}=\mathrm{P}<0.05$ compared with VM dual therapy). 

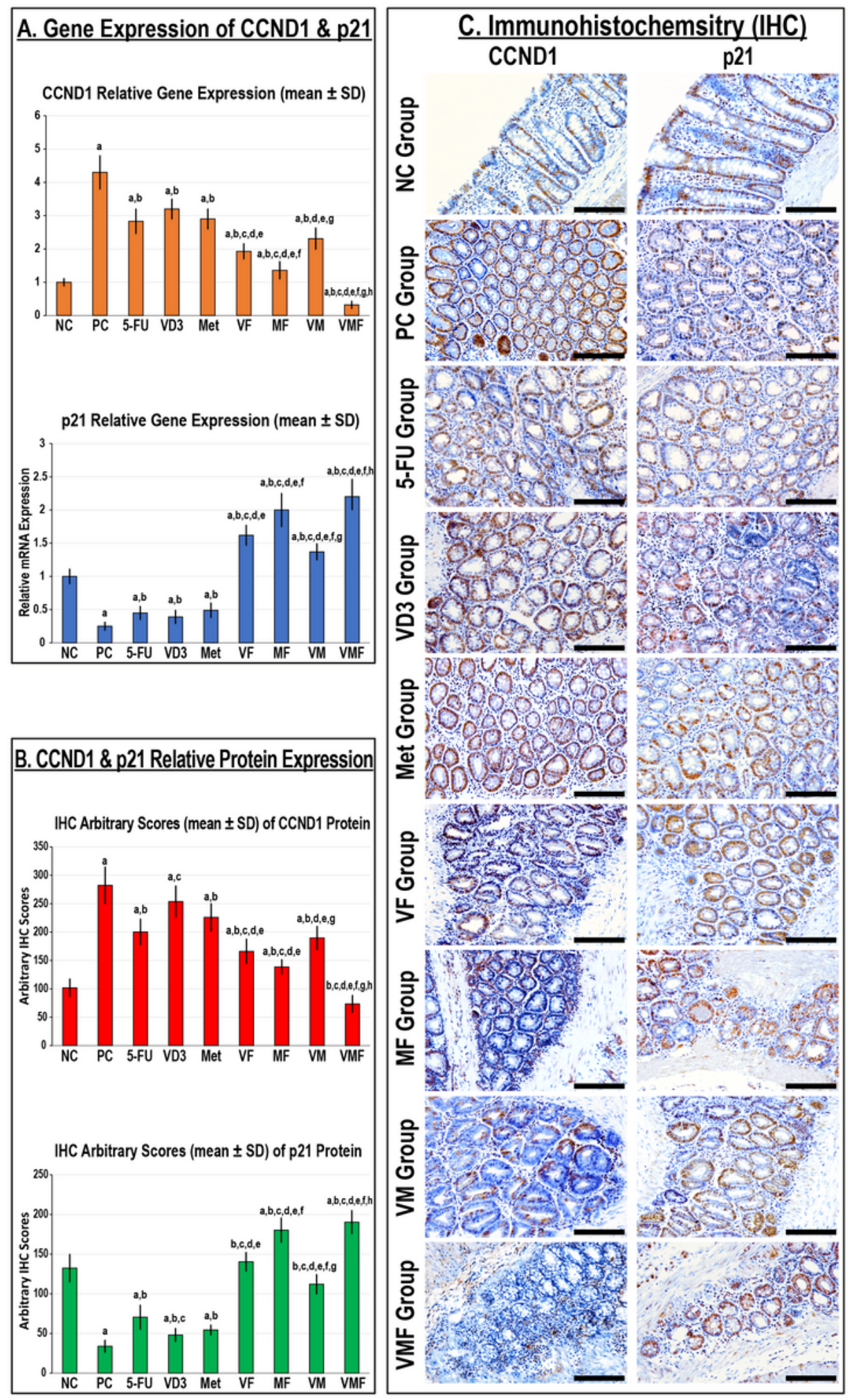

Figure 2

the relative (A) gene and (B) protein expression of the targeted molecules in colonic tissues from the different groups are shown as graph bars ( $\mathrm{n}=10 \mathrm{mice} / \mathrm{group}$; data was analysed by ANOVA followed by Tukey's HSD post-hoc test and is shown as mean \pm SD; $a=P<0.05$ compared with the NC group; $b=P<$ 0.05 compared with the $\mathrm{PC}$ group; $\mathrm{c}=\mathrm{P}<0.05$ compared with 5-FU monotherapy; $\mathrm{d}=\mathrm{P}<0.05$ compared $V_{D_{3}}$ monotherapy, $\mathrm{e}=\mathrm{P}<0.05$ compared with Met monotherapy; $\mathrm{f}=\mathrm{P}<0.05$ compared with VF dual 
therapy; $\mathrm{g}=\mathrm{P}<0.05$ compared with MF dual therapy and $\mathrm{h}=\mathrm{P}<0.05$ compared with VM dual therapy). Moreover, (C) Localisation of CCND1 and p21 proteins by immunohistochemistry (IHC) in colonic tissues from the different groups ( $n=10$ mice/group; $20 \times$ objective; Scale bar $=15 \mu \mathrm{m})$.

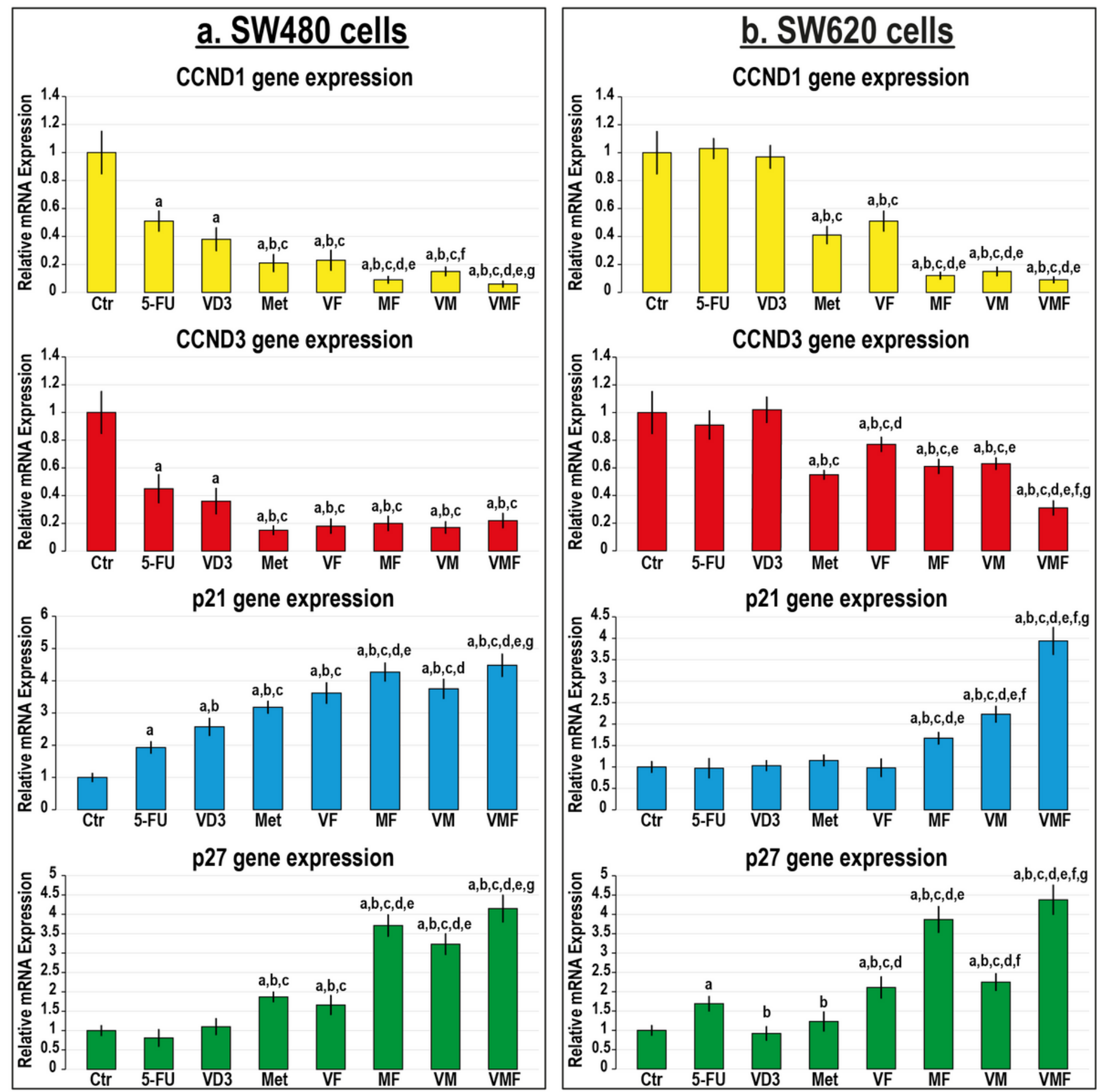

Figure 3

Percentages of cells (mean \pm SD) in the different phases of cell cycle in untreated control cells, and following treatments with 5-Fluorouracil, calcitriol and/or metformin single (5-FU, $\mathrm{VD}_{3}$ \& Met), dual (VF, MF \& VM), and triple (VMF) therapies for $12 \mathrm{~h}$ in the (a) SW480 and (b) SW620 colon cancer cell lines ( $\mathrm{n}=$ 
3/group; data was analysed by ANOVA followed by Games-Howell post-hoc test and is shown as mean \pm $\mathrm{SD} ; \mathrm{a}=\mathrm{P}<0.05$ compared with control untreated cells; $\mathrm{b}=\mathrm{P}<0.05$ compared with 5-FU monotherapy; $\mathrm{c}=$ $\mathrm{P}<0.05$ compared $\mathrm{VD}_{3}$ monotherapy, $\mathrm{d}=\mathrm{P}<0.05$ compared with Met monotherapy; $\mathrm{e}=\mathrm{P}<0.05$ compared with VF dual therapy; $f=P<0.05$ compared with MF dual therapy and $g=P<0.05$ compared with VM dual therapy).
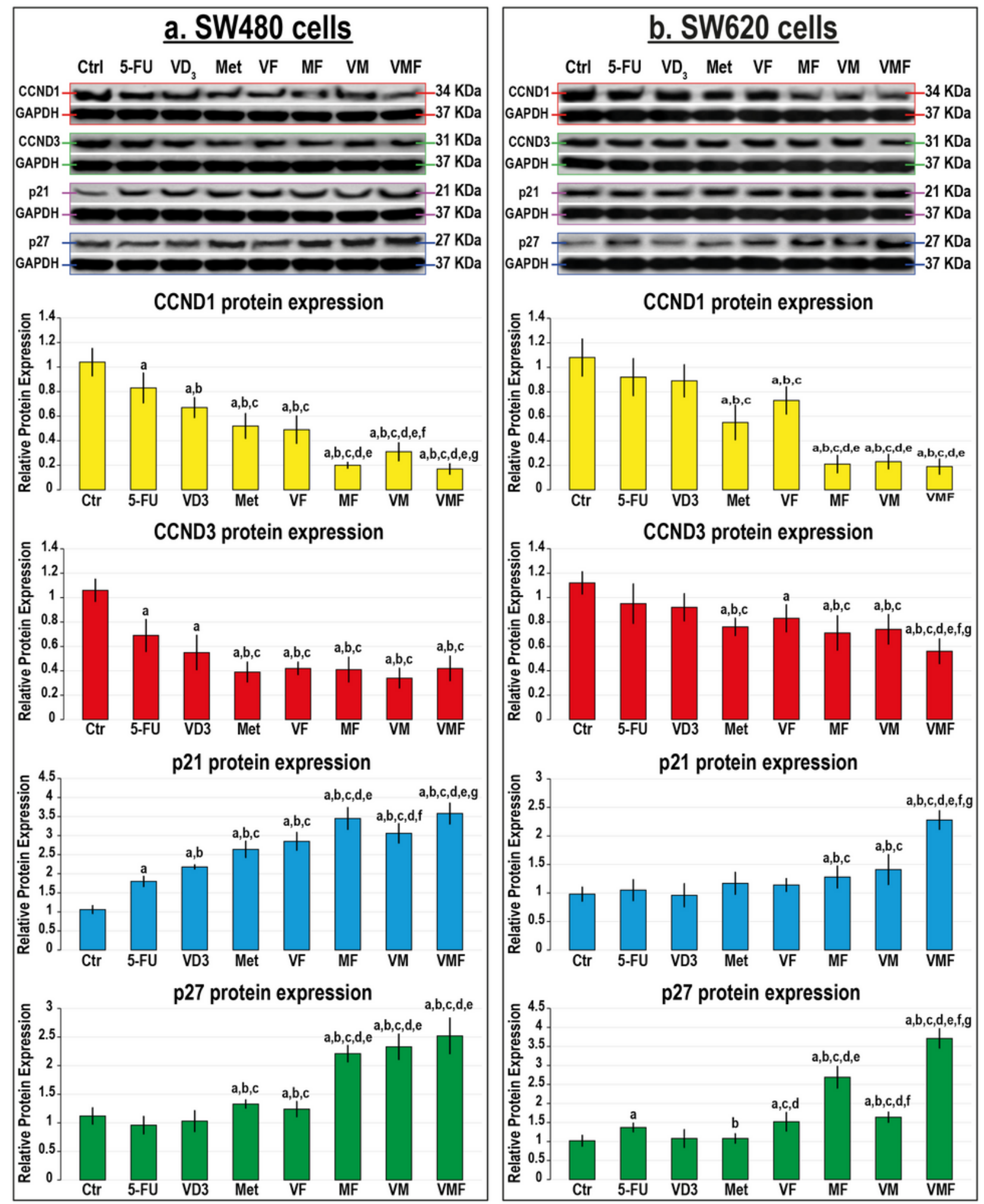

Figure 4 
Detection of CCND1, CCND3, p21 and p27 proteins by Western blot alongside their relative protein expression (mean $\pm \mathrm{SD}$ ) following treatments with 5-Fluorouracil, calcitriol and/or metformin single (5-FU, $\mathrm{VD}_{3}$ \& Met), dual (VF, MF \& VM), and triple (VMF) therapies for $12 \mathrm{~h}$ in the (a) SW480 and (b) SW620 colon cancer cell lines ( $n=3$ /group; data was analysed by ANOVA followed by Games-Howell post-hoc test and is shown as mean $\pm S D ; a=P<0.05$ compared with control untreated cells; $b=P<0.05$ compared with 5FU monotherapy; $\mathrm{c}=\mathrm{P}<0.05$ compared $\mathrm{VD}_{3}$ monotherapy, $\mathrm{d}=\mathrm{P}<0.05$ compared with Met monotherapy; $\mathrm{e}=\mathrm{P}<0.05$ compared with VF dual therapy; $\mathrm{f}=\mathrm{P}<0.05$ compared with MF dual therapy and $\mathrm{g}=\mathrm{P}<0.05$ compared with VM dual therapy). 

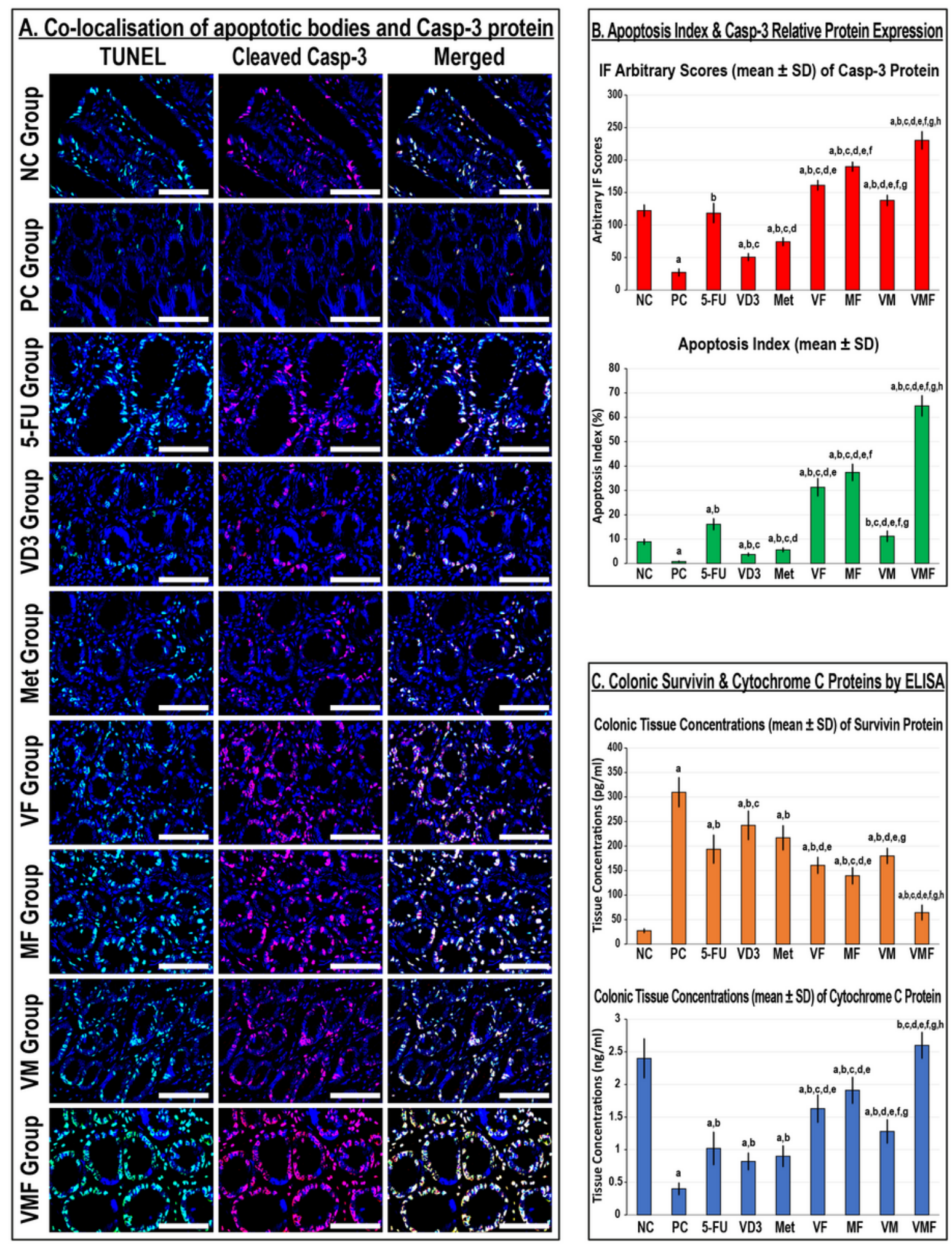

Figure 5

(A) Co-detection of apoptotic bodies by TUNEL (green) with cleaved Casp-3 (red) by immunofluorescence in the colonic tissues from all the study groups ( $n=10$ mice/group; $40 \times$ objective; scale bar $=8 \mu \mathrm{m}$ ).

Moreover, (B) the relative expression of Casp-3 protein alongside apoptosis index and (C) in the colonic tissues concentrations of survivin and cytochrome $\mathrm{C}$ proteins from all groups are displayed as graph bars ( $\mathrm{n}=10$ mice/group; data was analysed by ANOVA followed by Tukey's HSD test and is shown as mean \pm 
SD; $a=P<0.05$ compared with the NC group; $b=P<0.05$ compared with the $P C$ group; $=\mathrm{P}<0.05$ compared with 5-FU monotherapy; $\mathrm{d}=\mathrm{P}<0.05$ compared $\mathrm{VD}_{3}$ monotherapy, $\mathrm{e}=\mathrm{P}<0.05$ compared with Met monotherapy; $f=P<0.05$ compared with VF dual therapy; $g=P<0.05$ compared with MF dual therapy and $\mathrm{h}=\mathrm{P}<0.05$ compared with $\mathrm{VM}$ dual therapy).

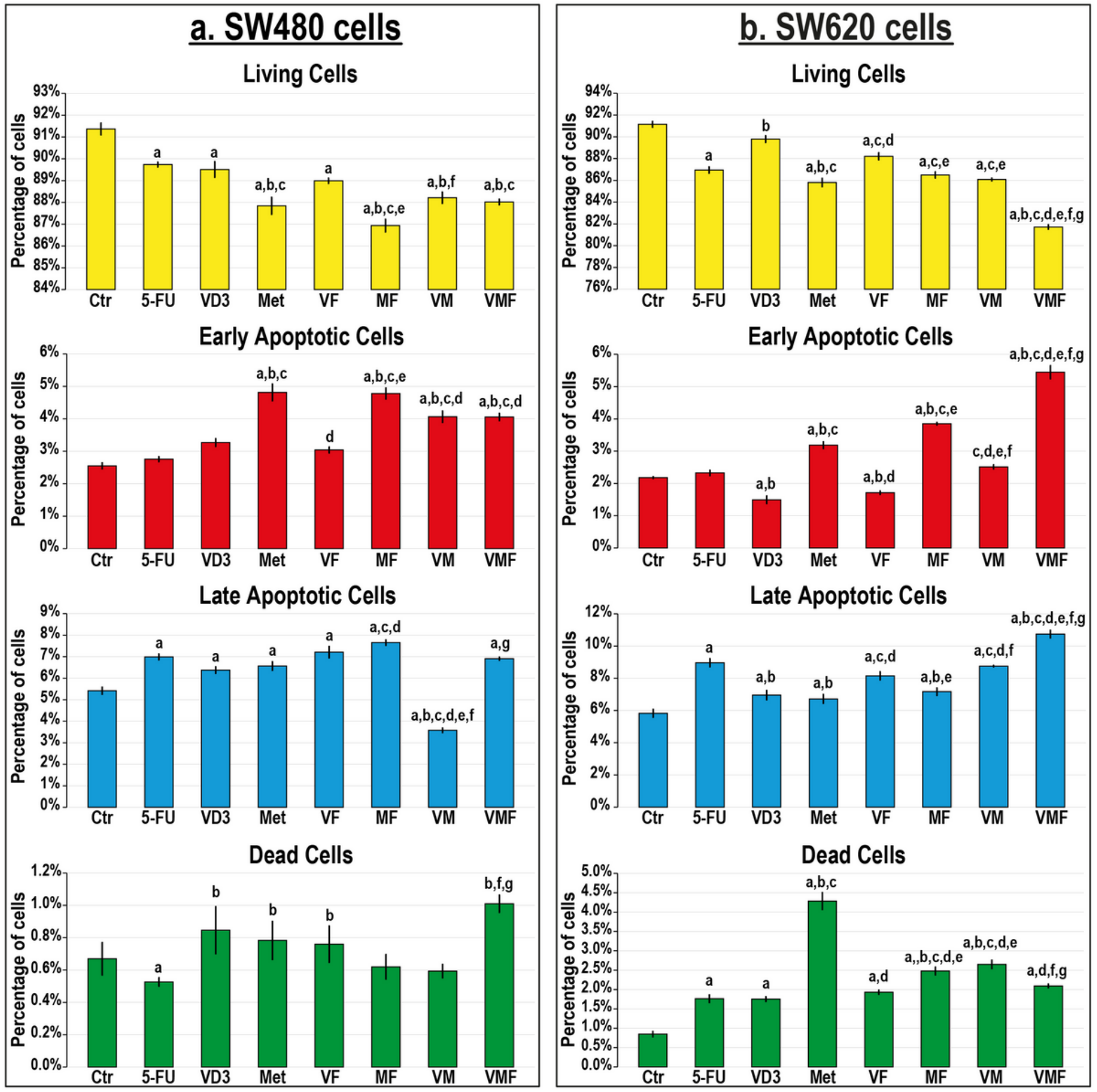

Figure 6 
Percentages (mean \pm SD) of living, early and late apoptotic alongside dead cells in untreated control cells, and following treatments with 5-Fluorouracil, calcitriol and/or metformin single (5-FU, $\mathrm{VD}_{3}$ \& Met), dual (VF, MF \& VM), and triple (VMF) therapies for $12 \mathrm{~h}$ in the (a) SW480 and (b) SW620 colon cancer cell lines ( $n=3$ /group; data was analysed by ANOVA followed by Games-Howell post-hoc tests and is shown as mean $\pm \mathrm{SD} ; \mathrm{a}=\mathrm{P}<0.05$ compared with control untreated cells; $\mathrm{b}=\mathrm{P}<0.05$ compared with 5-FU monotherapy; $\mathrm{C}=\mathrm{P}<0.05$ compared $\mathrm{VD}_{3}$ monotherapy, $\mathrm{d}=\mathrm{P}<0.05$ compared with Met monotherapy; $\mathrm{e}$ $=\mathrm{P}<0.05$ compared with VF dual therapy; $\mathrm{f}=\mathrm{P}<0.05$ compared with MF dual therapy and $\mathrm{g}=\mathrm{P}<0.05$ compared with VM dual therapy). 


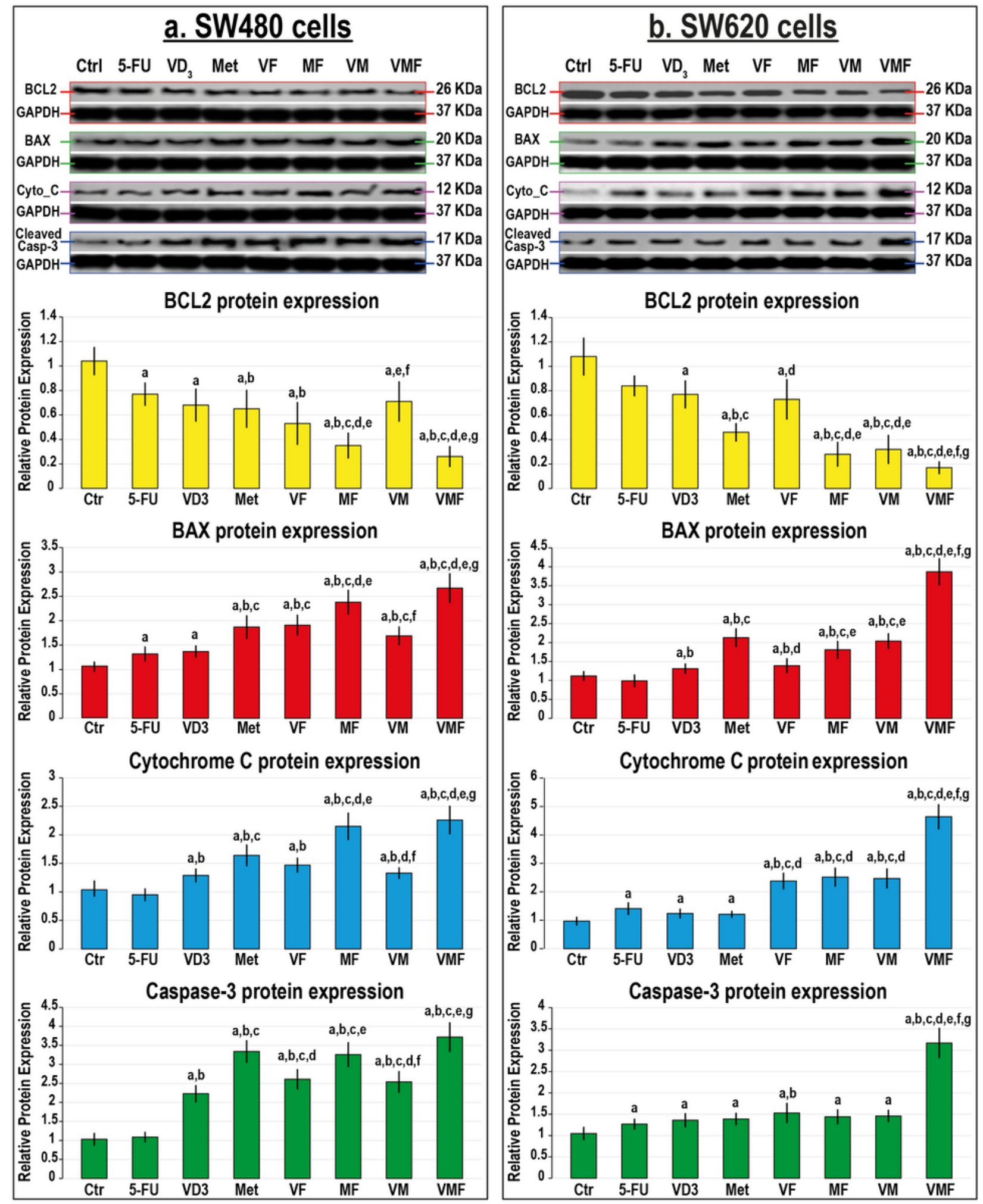

Figure 7

Detection of BCL2, BAX, Cytochrome $\mathrm{C}$ and cleaved caspase-3 proteins by Western blot alongside their relative protein expression (mean $\pm \mathrm{SD}$ ) following treatments with 5-Fluorouracil, calcitriol and/or metformin single (5-FU, $\mathrm{VD}_{3} \&$ Met), dual (VF, MF \& VM), and triple (VMF) therapies for $12 \mathrm{~h}$ in the (a) SW480 and (b) SW620 colon cancer cell lines ( $n=3$ /group; data was analysed by ANOVA followed by Games-Howell post-hoc test and is shown as mean \pm SD; a $=$ P $<0.05$ compared with control untreated 
cells; $\mathrm{b}=\mathrm{P}<0.05$ compared with 5-FU monotherapy; $\mathrm{c}=\mathrm{P}<0.05$ compared $\mathrm{VD}_{3}$ monotherapy, $\mathrm{d}=\mathrm{P}<$ 0.05 compared with Met monotherapy; $\mathrm{e}=\mathrm{P}<0.05$ compared with VF dual therapy; $\mathrm{f}=\mathrm{P}<0.05$ compared with MF dual therapy and $\mathrm{g}=\mathrm{P}<0.05$ compared with VM dual therapy).

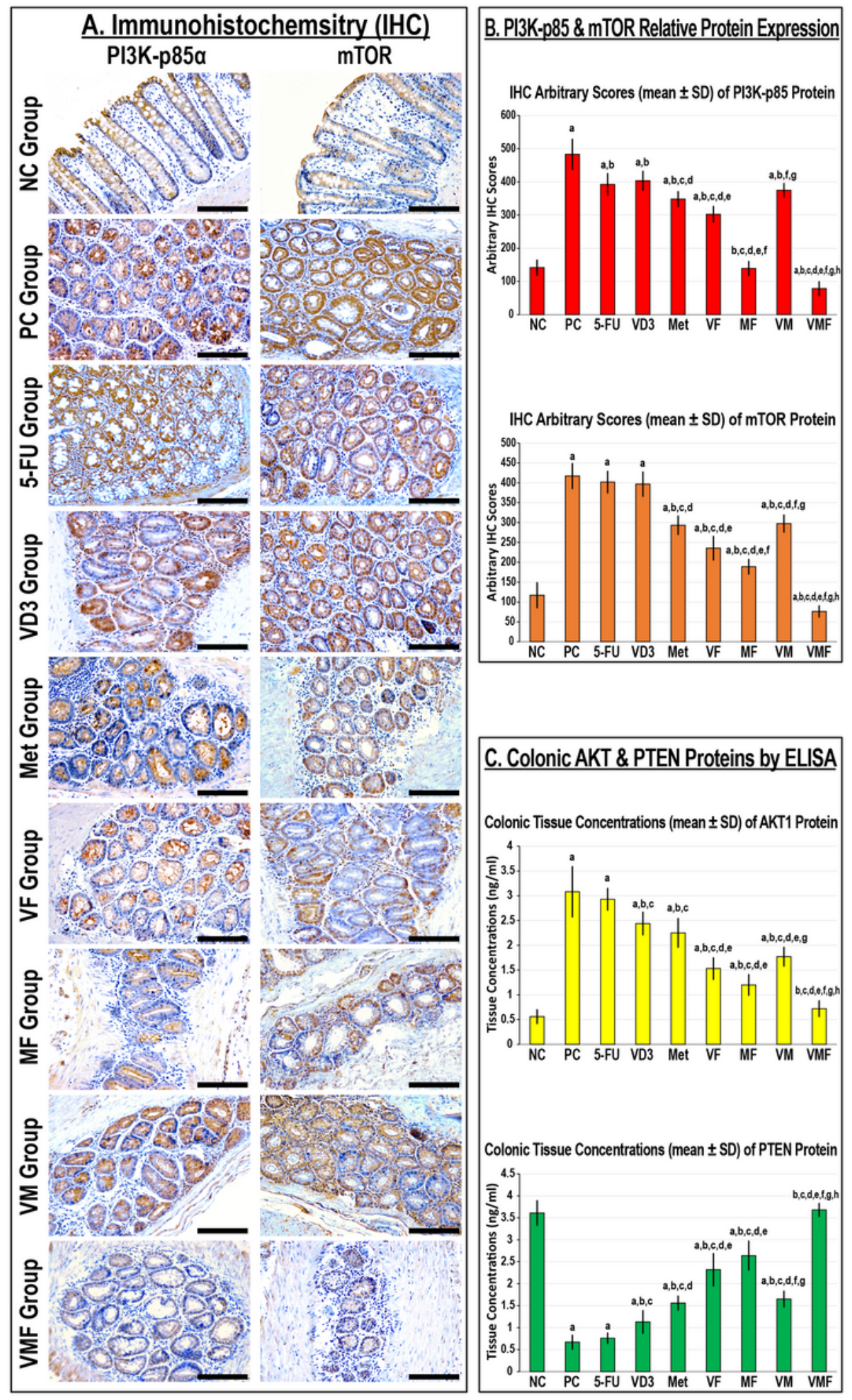

Figure 8 
Localisation of PI3K-p85a and mTOR proteins by immunohistochemistry (IHC) in colonic tissues from the different groups (20x objective; Scale bar $=15 \mu \mathrm{m}$ ). Additionally, $(B)$ the relative protein expression of PI3K-p85a and mTOR and (C) the colonic tissue concentrations of Akt1 and PTEN proteins in the different study groups are displayed as graph bars $(n=10$ mice/group; data was analysed by ANOVA followed by Tukey's HSD post-hoc test and is shown as mean \pm SD; $a=P<0.05$ compared with the NC group; $\mathrm{b}=\mathrm{P}<0.05$ compared with the $\mathrm{PC}$ group; $\mathrm{c}=\mathrm{P}<0.05$ compared with 5-FU monotherapy; $\mathrm{d}=\mathrm{P}<$ 0.05 compared $V_{3}$ monotherapy, $e=P<0.05$ compared with Met monotherapy; $f=P<0.05$ compared with VF dual therapy; $\mathrm{g}=\mathrm{P}<0.05$ compared with MF dual therapy and $\mathrm{h}=\mathrm{P}<0.05$ compared with $\mathrm{VM}$ dual therapy). 


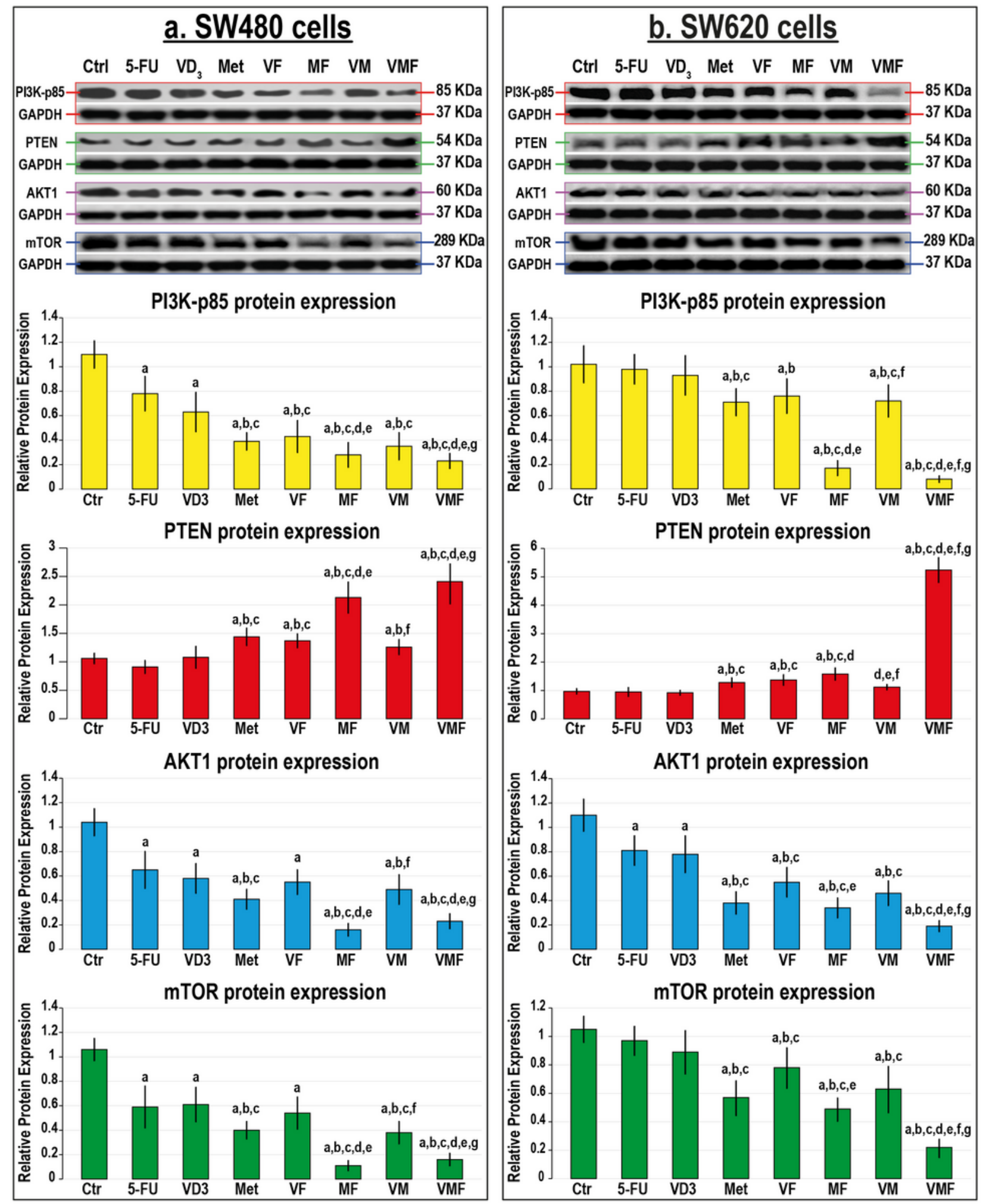

Figure 9

Detection of PI3K-p85a, PTEN, Akt1 and mTOR proteins by Western blot alongside their relative protein expression (mean $\pm \mathrm{SD}$ ) following treatments with 5-Fluorouracil, calcitriol and/or metformin single (5-FU, $V_{3}$ \& Met), dual (VF, MF \& VM), and triple (VMF) therapies for $12 \mathrm{~h}$ in the (a) SW480 and (b) SW620 colon cancer cell lines ( $n=3$ /group; data was analysed by ANOVA followed by Games-Howell post-hoc test and is shown as mean $\pm \mathrm{SD}$; $\mathrm{a}=\mathrm{P}<0.05$ compared with control untreated cells; $\mathrm{b}=\mathrm{P}<0.05$ compared with 5- 
FU monotherapy; $\mathrm{c}=\mathrm{P}<0.05$ compared $\mathrm{VD}_{3}$ monotherapy, $\mathrm{d}=\mathrm{P}<0.05$ compared with Met monotherapy; $\mathrm{e}=\mathrm{P}<0.05$ compared with VF dual therapy; $\mathrm{f}=\mathrm{P}<0.05$ compared with MF dual therapy and $\mathrm{g}=\mathrm{P}<0.05$ compared with VM dual therapy).

\section{Supplementary Files}

This is a list of supplementary files associated with this preprint. Click to download.

- Suppl.Figure1.tif

- Suppl.Figure2.jpg

- Suppl.Figure3.jpg

- Suppl.Figure4.jpg

- Suppl.Table1.docx 